\title{
AN EFFICIENT AND IMPROVED METHOD FOR THE BIGINELLI REACTION USING SOLID SUPERACID (SULPHATED $\mathrm{SnO}_{2}$ )
}

\author{
Rajesh S. Bhosale.`. Arshad M. Hashmi," P. K. Zubaidha," M. K. Dongre. \\ a) School of Chemical Sciences. S. R. T. M. University. Nanded - 431606. India \\ b) Catalysis Division. National Chemical Laboratory. Pune - 411008. India
}

\begin{abstract}
One-pot synthesis of 3,4-dihydropyrimidin-2(IH)-one (DHPM) has been effected efficiently by coupling of the three components, aldehyde, ethyl acetoacetate and urea / thiourea in the presence of solid superacid (sulphated $\mathrm{SnO}_{2}$ ). The method presented herein is attractive with respect to yield, reaction time. workup procedure and reusable catalyst.
\end{abstract}

Key words: Biginelli. DHPM, Sulphated $\mathrm{SnO}_{2}$.

The literature survey reveals that 3,4-dihydropyrimidin-2(IH)-ones (DHPMs) find wide therapeutic applications, such as antiviral, antitumor, antibacterial, anti-inflammatory agents.' Many biologicaly active marine alkaloids contain dihydropyrimidinones as the potent core unit. ${ }^{2-4}$ The most widely used marine alkaloids

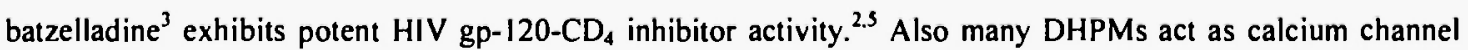
modulators, $\alpha_{1 \mathrm{a}}$-antagonists and neuropeptide $\mathrm{Y}(\mathrm{NPY})$ antagonists. ${ }^{1.6}$ As a consequence their synthesis has received considerable attention.

As part of the on going project on the application of solid superacid S-SnO $\mathrm{O}_{2}$ in organic synthesis, we explored its utility in Biginelli reaction (Scheme-1). A number of useful and reliable methods exist for Biginelli reaction ${ }^{7}$ using a variety of strong Lewis acids as well as protic acids as promoters. ${ }^{89}$ However, some of these methods are associated with certain drawbacks such as costly reagents, harsh reaction conditions, complex experimental process, and long reaction times. Also most of the reported catalysts work under homogeneous conditions and hence their recovery and reuse may be tedious. The recent developments include improvement of the well established procedures using new reagents, such as cadmium chloride, niobium (V) chloride, L-Proline, $\mathrm{Ag}_{3} \mathrm{PW}_{12} \mathrm{O}_{40}$ and iodine. ${ }^{10}$ Herein we introduce a new catalyst for synthesis of DHPMs with improvements interms of reaction conditions, reaction time, and use of eco-friendly reusable catalyst.

Solid superacids have been widely employed in petrochemical industries. In recent years, solid superacids $^{11.12}$ have attracted much interest in organic synthesis because of their high reactivity, stability and selectivity. Among them sulphated $\mathrm{SnO}_{2}$ has gained much attention, due to its high acidity, ease of handling. low toxicity, moisture and air stability.

The present protocol describes a new, efficient and environmentally benign procedure for the synthesis of 3,4-dihydropyrimidin-2( $\mid H$ )-ones (DHPMs) using solid superacid (sulphated $\mathrm{SnO}_{2}$ ). The reaction of benzaldehyde (10 $\mathrm{mmol})$, ethyl acetoacetate $(10 \mathrm{mmol})$, and urea $(15 \mathrm{mmol})$ was carried out in the presence of sulphated $\mathrm{SnO}_{2}(10 \%$ by weight $)$ in toluene $(10 \mathrm{~mL})$ at reflux temperature. The reaction proceeded smoothly to afford the corresponding 3,4-dihydropyrimidin-2(1H)-ones in $94 \%$ yield within 45 minutes. After cooling the reaction mixture, toluene was removed under reduced pressure, and hot methanol was added and filtered to separate solid catalyst from the product. The filtrate on cooling afforded the desired product in pure crystalline form. Also reaction of aromatic aldehydes bearing electron donating and withdrawing groups on aromatic ring underwent smooth conversion to afford the corresponding 3,4-dihydropyrimidin-2( $1 H)$-ones in good to 
excellent yields without affecting the functional groups such as, thiophene, halogen, ether, ester, vinyl and nitro moieties. Aliphatic aldehydes (entries 12 and 14) also reacted efficiently to afford the corresponding DHPMs. All the reactions (Table-1) required conversion period of 40-70 minutes to afford the desired product. The obtained products were characterized by spectroscopic methods (IR, 'H NMR, ${ }^{13} \mathrm{C}$ NMR) and by comparison of physical constant with authentic samples. The residual catalyst can be recycled and reused thrice without appreciable degree of catalyst deactivation.

The effectiveness of our protocol is reflected in work-up procedure, short reaction time and use of cheap recyclable catalyst. The most striking feature is that the procedure works equally well for the sensitive aldehyde bearing guanosine base (entry 13$)^{10 \mathrm{e}}$ and afford $4 \mathrm{~m} 91 \%$ yield.

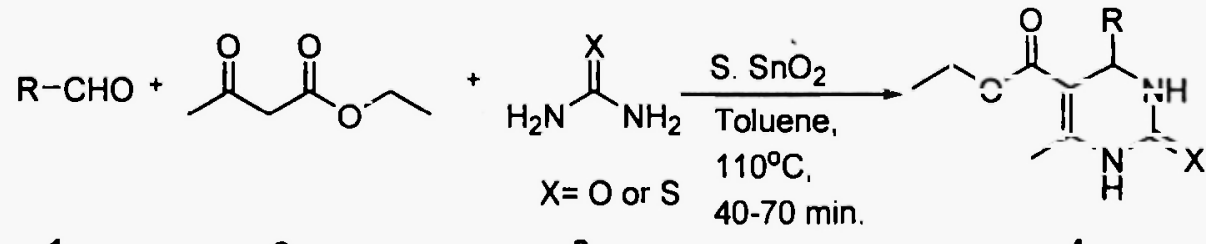

1

2

3

4

Scheme-1

Based on literature' we speculate that reaction proceeds via acyl imine intermidiate formed from condensation of aldehyde and urea. Subsequent addition of $\beta$-keto ester enolate, followed by cyclization and dehydration afford the dihydropyrimidinone. Sulphated $\mathrm{SnO}_{2}$ may play crucial role in accelerating the dehydrative steps and enolization of $\beta$-keto ester.

\section{Experimental Section}

Typical procedure for preparation of 3,4-dihydropyrimidin-2( $(\mathrm{H})$-ones: A mixture of aldehyde $\mathbf{I}(\mathrm{a}-\mathrm{o})(10$ mmol), ethyl acetoacetate $2(10 \mathrm{mmol})$, urea $3(15 \mathrm{mmol})$ and $\mathrm{S} . \mathrm{SnO}_{2}(10 \%$ by weight) in toluene $(10 \mathrm{~mL})$ was stirred at reflux temperature $\left(110^{\circ} \mathrm{C}\right)$. The progress of the reaction was monitored by TLC. On completion (40$70 \mathrm{~min}$.), the solvent was removed under reduced pressure. The residual part was dissolved in hot methanol and filtered to recover catalyst, and cooling of the filtrate afforded pure crystalline dihydropyrimidinone (DHPM). The physical constant and spectral data IR, ${ }^{~} \mathrm{H}$ NMR, ${ }^{13} \mathrm{C}$ NMR for DHPMs (Table-I) were identified with those of authentic samples. The separated catalyst was heated at $120^{\circ} \mathrm{C}$ for $4 \mathrm{hrs}$ and reused.

In conclusion, our result show that sulphated $\mathrm{SnO}_{2}$ is a mild and highly efficient solid acid for the one pot Biginelli synthesis of 3,4-dihydropyrimidin-2(lH)-ones. The catalyst was separated and reused several times. Compared to the reported process, 3,4-dihydropyrimidin-2(lH)-ones synthesized over solid acid catalyst were clean and the present environmentally friendly process involves simple workup procedure. This new method offer significant improvements over the existing procedures in tenns of reaction time, yields and facilitate facile synthesis of potentially bioactive 3,4-dihydropyrimidin-2(IH)-ones. 


\begin{tabular}{|c|c|c|c|c|}
\hline Entry & Substrate $1(a-n)$ & Product & Time (min) & Yield(\%) \\
\hline 1 & $\mathrm{CHO}$ & $4 a$ & 45 & 94 \\
\hline 2 & $\mathrm{CHO}$ & $4 b$ & 50 & 93 \\
\hline 3 & $\mathrm{CHO}$ & $4 c$ & 56 & 92 \\
\hline 4 & $\mathrm{CHO}$ & $4 d$ & 55 & 89 \\
\hline 5 & & $4 e$ & 50 & 92 \\
\hline 6 & & $4 f$ & 45 & 90 \\
\hline 7 & & $\mathbf{4 g}$ & 40 & 95 \\
\hline 8 & & $4 h$ & 55 & 87 \\
\hline 9 & & $4 i$ & 50 & 89 \\
\hline 10 & & $4 j$ & 65 & 80 \\
\hline 11 & & $4 k$ & 55 & 90 \\
\hline 12 & & 41 & 50 & 92 \\
\hline 13 & & $4 m$ & 60 & 91 \\
\hline 14 & $\mathrm{H}_{3}\left(\mathrm{CH}_{2}\right)_{3} \mathrm{CHO}$ & $4 n$ & 70 & 82 \\
\hline $15^{d}$ & & 40 & 50 & 90 \\
\hline
\end{tabular}

a: All the products were characterized by IR, ${ }^{1} \mathrm{H}-\mathrm{NMr}$, and ${ }^{13} \mathrm{C}-\mathrm{NMR}$.

b: Isolated yield.

c: $\mathbf{R}^{\prime}=\left(\mathrm{CH}_{3}\right)_{2} \mathrm{CHCO}$

d. Thiourea 


\section{References}

1. (a) C. O. Kappe, Tetrahedron 49,69379 (1993) and references cited therein. (b) C. O. Kappe, Acc. Chem. Res. 33, 879 (2000).

2. B. B. Sanider, Z. Shi, J. Org. Chem. 58, 3828 (1993) and refrences therein.

3. A. D. Patil, N. V. Kumar, W. C. Kokke, M. F. Bean, A. J. Freyer, C. DeBrosse, S. Mai, A. Trunesh, D. T. Faulkner, B. Carte, A. L. Breen, R. P. Hertzberg, R. K. Johnson, J. W. Westley, B. C. M. Potts, J. Org. Chem. 60, I182(1995).

4. (a) Y. Kashnan, S. Hirsh, O. J. McConnel, I. Ohtani, K. Takenori, H. Kakisawa, J. Am. Chem. Soc. III, 8925(1989). (b) I. Ohtani, T. Kusumi, H. Kakisawa, Y. Kashman, J. Am. Chem. Soc. 11 4, 8472(1992).

5. B. B. Snider, J. Chen, A. D. Patil, A. Freyer, Tetrahedron Letl. 37, 6977(1996).

6. (a) G. C. Rovnyak, S. D. Kimball, G. Cucinotta, J. D. Dimareo, J. Gougoutas, A. Hedberg, M. Malley, J. P. MaCarthy, R. Zhang, S. Moreland, J. Med. Chem. 38, 1199(1995). (b) K. S. Atwall, G. C. Rovnyak, S. D. Kimball, D. M. Floyd, S. Moreland, B. N. Swanson, J. Z. Gougoutas, J. Schwartz. K. M. Smillie, M. F. Molley, J. Med. Chem. 33, 2629 (1990). (c) K. S. Atwall, B. N. Swanson, S. E. Unger, D. M. Floyd, S. Moreland, A. Hedberg. B. C. O'Reilly, J. Med. Chem. 34, 8069(1991). (d) G. J. Grover, S. Dzwonezyk, D. M. McMullen, C. S. Normadinam, P. G. Sleph, S. J. Moreland, J. Cardiovas. Pharmacol. 26, 289(1995).

7. P. Biginelli, Gazz. Chim. Ital. 23, 3609(1893).

8. (a) P. Salehi, M. Dabiri, M. A. Zolfigol, M. A. B. Fard, Tetrahedron Lett. 44, 2889(2003). (b) G. Maiti, P. Kundu, C. Guin, Tetrahedron Letl. 44, 2757(2003). (c) N. Y. Fu, Y. F. Yuan, Z. Cao, S. W. Wang, J. T. Wang, C. Peppe, Tetrahedron, 58, 480I(2002). (d) J. Lu, Y. Bai, Synthesis, 466-470(2002). (e) J. S. Yadav, B. V. S. Reddy, K. B. Reddy, K. S. Raj, A. R. Prasad, J. Chem. Soc. Perkin Trans. 1, 1939(2001). (f) J. Peng, Y. Deng, Tetrahedron Lell. 42, 5917(2001). (g) B. C. Ranu, A. Hajra, U. Jana, J. Org. Chem. 65, 6270(2000). (h) Y. M. C. Quin, L. Wang, M. Yang, J. Org. Chem. 65, 3864(2000).

9. (a) R. Varla, M. Alam, S. R. Adapa, Synlett. 67-70(2003). (b) F. Bigi, S. Carloni, B. Frullanti, R, Maggi, G. Sartori, Tetrahedron Lett. 40, 3465(1999). (c) Y. X. Li., W. L. Bao, Chin. Chem. Lett., 14, 993(2003). (d) V. R. Choudhary, V. H. Tillu, V. S. Narkhede, H. B. Borate, R. D. Wakharkar, Calal. Commun. 4, 449(2003).

10. (a) A. V. Narsaiah, A. K. Basak, K. Nagaiah, K. Synthesis, 1253(2004). (b) J. S. Yadav, B. V. S. Reddy, J. J. Naidu, K. Sadashiv, Chem. Letl. 33, 926(2004). (c) J. S. Yadav, S. Praveen Kumar, G. Kondaji, R. Srinivasa Rao, K. Nagaiah, Chem. Lett. 33, $1168(2004)$. (d) J. S. Yadav, B. V. S. Reddy, P. Sridhar, J. S. S. Reddy, K. Nagaiah, N. Lingaiah, P. S. Saiprasad, Eur. J. Org. Chem. 552(2004). (e) R. S. Bhosale, Sid. V. Bhosale, She. V. Bhosale, T. Wang, P. K. Zubaidha, Tetrahedron Lett. 45, 9111 (2004).

II. G. Qian, R. Zhao, D. Ji, G. Lu, Y. Qi, J. Suo, Chemistry Lett. 33, 834(2004).

12. (a) S. P. Chavan, P. K. Zubaidha, S. W. Dantale, A. Keshavaraja, A. V. Ramaswamy, T. Ravindranathan, Tetrahedron Lett. 37, 233(1996). (b) S. P. Chavan, P. K. Zubaidha, S. W. Dantale, A. Keshavaraja, A. V. Ramaswamy, T. Ravindranathan, Tetrahedron Lett. 37, 237(1996).

Received on December 22, 2004 